The key questions about rationing once its inevitability has been accepted are who should do it and how it should be done. The BMA's document Leading for Health asks both of these questions. ${ }^{7}$ Traditionally, doctors have taken the lead but at the operating table and the bedside rather than in open forums. Sir Raymond Hoffenberg stated clearly the traditional view in this year's Harveian oration: "If services are to be limited," he said, "I would rather see it done implicitlyunstated, unwritten, unacknowledged - in the curious and not inhumane way in which such matters are managed in the United Kingdom."

Sir Raymond has misread the zeitgeist. Democracy in all its messy splendour is taking over everywhere; older democracies like Britain are talking of citizen's charters; and professions are suspect. The decline of paternalism and the rightful increase in demands for accountability mean that doctors cannot take such decisions alone or simply within the profession. Nurses and other health professionals must be involved and so must managers; they at least are used to working within environments where resources are never adequate to pursue all projects. The difficult people to involve in the decisions are those who in the end matter most: politicians and the public. Politicians are scared by explicit rationing and become vulnerable if they run too far ahead of the electorate, but they must begin to draw the public into the debate. Their problem is that the public is more likely to accuse them of meanness than admire them for forward thinking. But some politicians have begun to speak about the issue. $^{8}$

Especially difficult is to involve the public in detailed decision making in the way that was achieved at least partially in Oregon. Health authorities may need to be much more accountable than they are at the moment if they are to make their difficult decisions with confidence, and authorities may need to look at devices like opinion polls if they are to find out what the public really thinks. ${ }^{9}$

The two disciplines that have the most to offer to the how of rationing are philosphy and economics, and both are building up considerable bodies of thought on the subject. Ideas that judgments might be made in terms of gender, age, income, economic value, or moral worthiness (as has often happened) become hard to sustain in the sandblaster of ethical argument, and the debate inevitably drifts back to some sort of utilitarianism or cost-benefit analysis.

Many people accept that it feels ethically doubtful to devote large amounts of resources to achieve small benefit (even if that benefit is something as precious as prolonging the life of a child) when much greater benefit could be achieved by spending those resources elsewhere. Yet many people who would accept this general line of argument become upset by the thought of using techniques like QALYs (quality adjusted life years) to help make these difficult decisions. But often the worry is misplaced: even the greatest enthusiasts for QALYs argue that they are aids to analysis, not substitutes for thought. ${ }^{10}$ Better than abandoning them because of their many technical imperfections is struggling to improve them and to develop other techniques that will help allocate resources in a fairer and more rational way.

The debate on rationing health care in Britain has still to get fully underway in the community at large. The BMA has put it on the agenda in Leading for Health, but little is likely to be heard on the subject before the election. The debate should move beyond whether there is a need to make difficult decisions on allocating resources and concentrate on who should make them and how. Although it is tempting to leave the decisons to be fudged by kindly professionals, I believe that we should follow the Oregonians into the sunlight. Ways need to be found of combining public opinion with improved technical measures of cost and effectiveness to make the difficult choices inherent in allocating resources.

Editor, $B M F$

RICHARD SMITH

1 Moss AH, Siegler M. Should alcoholics compete equally for liver transplantation? JAMA 1991;265:1295-8

2 Thwaithes B. The NHS: the end of the rainbow. Southampton: Institute for Healthy Policy Studies, 1987.

3 Oregon Health Services Commission. Prioritisation of health services. Portland: Oregon Health Services Commission, 1991

Klein R. On the Oregon trail: rationing health care. BMF 1991;302:1-2.

Fox DM, Leichter HM. Rationing care in Oregon: the new accountability. Health Affairs 1991;Summer:7-27.

6 Mathews L. Health reforms in New Zealand. BMF 1991;303:327.

7 BMA. Leading for health: a BMA agenda for health. London: BMA, 199

8 Beecham L. Liberal Democrats' pillars for health. BMF 1991;303:1554.

9 Lewis PA, Charny $M$. Which of two individuals do you treat when only their ages are different and you can't treat both? F Med Ethics 1989;15:28-32.

10 Williams A. Is the QALY a technical solution to a political problem? Of course not. In $\mathcal{f}$ Health Serv 1991;21:365-9.

\title{
Physicians for Human Rights (UK)
}

\section{Showing early promise}

Physicians for Human Rights (UK) was launched two years ago. Its constitution, drafted by a steering committee chaired by a former editor of the Lancet, Ian Munro, was approved at its first annual general meeting 12 months later. Is there really room for another medical group promoting human rights?

Doctors are singularly well suited to investigating abuses of human rights. They are perceived as independent, intelligent, and conscientious professionals, and the medical code of ethics is universally respected. Such a reputation encourages victims and witnesses to offer information, it discourages bureaucratic obstruction, and it lends authority to what doctors say.

But there is much more to it than that. People are accustomed to trust doctors with sensitive information, and doctors are experienced at dealing with distress. They are trained to evaluate information impartially, even in difficult circumstances, and to perform physical examinations and take specimens. Medical specialists are responsible for more specialised investigations such as necropsy, psychiatric assessment, and biochemical analyses. And importantly for the success of campaigns condemning medical participation in abuse, peer group assessment is required before pressure can be exerted, which has occurred in response to the abuse in Soviet psychiatry.'

The principal purpose of Physicians for Human Rights is to exploit these unique characteristics in investigating abuse of human rights. The four other aims are of similar importance: to defend health care workers persecuted for their beliefs or for practising ethically; to educate people about the physical $\delta$ and psychological consequences of abuse; to expose medical participation in abuse; and to promote cooperation between $\stackrel{\oplus}{\partial}$ medical and other human rights organisations.

These are fine ideals, but what has the group achieved one year on from its first Annual General Meeting? Most notably, 
it has completed four investigations into human rights. The investigation in Kashmir was the first independent assessment in the region. It was called for by a chairman of surgery who had been required to falsify figures for casualties. Because Amnesty International had been repeatedly refused entry, two members of the group flew in as tourists at some personal risk. On returning they were invited to give evidence before the parliamentary committee on human rights and their report was forwarded to the Prime Minister. ${ }^{2}$ Physicians for Human Rights was the first human rights organisation to enter Kuwait City after its liberation. Evidence of violations that had taken place before and after the Iraqi withdrawal were recorded and relevant information was passed to the International Red Cross and the British foreign secretary before his meeting with the Emir. ${ }^{3}$ More recently the group has completed two studies in conjunction with the Dutch Johannes Wier Foundation: one in South Africa assessing progress towards the elimination of racial inequality in the provision of health care and the other in Yugoslavia examining the effect of the ethnic conflict on medical services and the conduct of doctors. ${ }^{+}$

Clearly, an independent and non-political human rights organisation that can rapidly deploy the requisite medical skill to where it is needed has a valuable part to play. The future depends on the members' response to the challenges ahead, but it also depends on winning wider support from the medical profession. The more members there are the broader will be the range of skills on which the organisation may draw and the more effective and influential it will become. At present the organisation's activities are financed almost entirely from subscriptions. Membership is open to all doctors, medical students, and health care workers. Such is

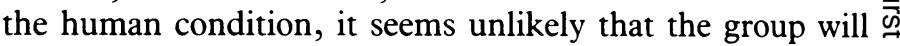
ever find itself out of a job, however large it grows.

Annual membership costs $£ 20$ a year ( $£ 10$ for students). Inquiries to the Physicians for Human Rights (UK), C/o University Department $\stackrel{\mathbb{Q}}{\Omega}$ of Forensic Medicine, Royal Infirmary, Dundee DD1 9ND.

Treasurer, Physicians for Human Rights UK,

PETER HALL $\vec{\circ}$

Leavesden Hospital, Watford WD5 0NU

1 World Psychiatric Association. Report by the World Psychiatric Association team of the visit to the Soviet Union (9-29 June 1991). London: Royal College of Psychiatrists, 1991.

2 Physicians for Human Rights (UK). Kashmire 1991: health consequences of civil unrest and the police $\omega$ and military action. Dundee: University Department of Forensic Medicine, Royal Infirmary, 1991. 3. Physicians for Human Rights (UK). Kuwait 1991: human rights abuses and effects on the health care $\mathcal{O}^{\circ}$ system during and after the Iraqi occupation. Dundee: University Department of Forensic Medicine, Royal Infirmary, 1991.

4 Physicians for Human Rights (UK). South Africa 1991: apartheid and health care in transition-a report on progress, impediments and means of support. Dundee: University Department of Forensic $\mathcal{G}$ Medicine, Royal Infirmary, 1991

\section{On lightning}

\section{Hair standing on end may be warning of an impending strike}

\author{
The common cormorant or shag \\ Lays eggs inside a paper bag. \\ The reason you will see no doubt - \\ It is to keep the lightning out. \\ But what these unobservant birds \\ Have never noticed is that herds \\ Of wandering bears may come with buns \\ And steal the bags to hold the crumbs.
}

Anon

Being struck by lightning is a remote chance in England and Wales: about five people are killed in this way in an average year. ${ }^{1}$ Doctors sometimes use the statistic to put other remote risks into perspective (deaths from rabies, for example, are far less common than deaths from lightning in Britain and even in countries such as the United States, where the disease is endemic). Such analogies, however, should be used carefully outside Europe. Lightning strikes are much more common in tropical countries. From 1965 to 1972 there were 430 deaths from lightning in Rhodesia (now Zimbabwe), which at that time had a population of less than four million. ${ }^{2}$ Deaths on the road were only five times more frequent.

Thunderstorms become increasingly common as the air temperature rises, and they occur more often in mountainous country. Around the world at any moment there are close to 2000 thunderstorms in progress and lightning strikes the earth 6000 times a minute. The mortality from lightning is largely determined by geographical factors, but population density and behaviour both play a part. In the nineteenth century the annual death toll in England and Wales was 20, four times the present figure, and the same downward trend in deaths has been seen in other countries as a smaller proportion of adults have worked outdoors. Hills, open country, and open stretches of water are dangerous places in thunderstorms-and included in this category are golf courses, where deaths are not unusual.

Someone caught in a thunderstorm should take sensible precautions. Get indoors if possible; inside a car is usually safe, too. Outdoors, throw away any metal or conductive object you may be holding - a golf club, a carbon fibre fishing rod, a gun - and don't use an umbrella. Don't shelter under a tree, and especially not an isolated tree. Oaks have $a \stackrel{\Phi}{\Phi}$ reputation for attracting lightning. Warning of an impending $\overrightarrow{\vec{O}}$ strike may be given by your hair standing on end. If this $\exists$ occurs crouch into a ball with your legs together.

Indoors, consider unplugging the television aerial (this may? save you having to watch the set explode). Don't use the telephone-a survey in Australia found that 60 people a year were injured by lightning strikes being conducted along the을 wires to the handset; many were physically injured, and $10 \% \frac{3}{\circ}$ lost consciousness. ${ }^{3}$

For every person killed by a lightning strike four or more

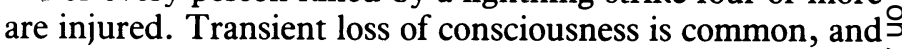
some victims become temporarily blind or deaf. Burns may 0 appear over the course of several hours. ${ }^{4}$ The most frequent $\frac{}{0}$ cause of death is cardiac arrest, which may be due to ventricular fibrillation or asystole. Aggressive resuscitation $\tilde{D}^{-}$ measures are warranted, especially if a pulse is present or is $\omega$ restored, as the return of spontaneous respiration may be much delayed.

Lightning does strike in the same place twice-quite commonly. Tall buildings are hit repeatedly, often in a single thunderstorm. And Elsom describes a former park rangerō who was struck by lightning in 1942, when he lost a toe nail; again in 1969, 1970, and 1972 - when his hair was set alight; $;$ in 1973, when his regrown hair burnt again; and in 1976 ando 1977. ' Travellers to the tropics, beware.

Associate Editor, $B M \mathcal{F}$

TONY SMITHE

1 Elsom D. Learn to live with lightning. New Scientist 1989 June 24:54-8

2 Castle WM, Kreft J. A survey of deaths in Rhodesia caused by lightning. Cent Afr 7 Med 1974;20:93-5.

3 Andrews $\mathrm{CJ}$, Darveniza $M$. Telephone mediated lightning injury: an Australian survey. $\mathcal{F}$ Trauma 1989.29:665-71.

4 Ghezzi KT. Lightning injuries. Postgrad Med 1989;85:197-207. 